\title{
Erratum to: Squeezing rock conditions at phyllite-slate zone in Golab water conveyance tunnel, Iran: A case study
}

\author{
Rahmati Asghar, Faramarzi Lohrasb, Darbor Mohammad \\ Department of Mining Engineering, Isfahan University of Technology, Isfahan, 84156-83111, Iran \\ (C) Central South University Press and Springer-Verlag GmbH Germany, part of Springer Nature 2017
}

Erratum to: J. Cent. South Univ. (2017) 24: 2475-2485

DOI: https://doi.org/10.1007/s11771-017-3659-6

Authors' first and last names were interchanged in the original version of the article and they should be replaced as follows: Asghar Rahmati, Lohrasb Faramarzi, Mohammad Darbor.

The online version of the original article can be found at https://doi.org/10.1007/s11771-017-3659-6 